\title{
A VIABILIDADE DO SISTEMA LIGHT STEEL FRAME PARA CONSTRUÇÕES RESIDENCIAIS
}

\section{THE LIGHT STEEL FREMA SYSTEM VIABILITY FOR RESIDENTIAL BUILDINGS}

\author{
Gabriel Sperandio Milan ${ }^{1}$; Roger Vagner Novello ${ }^{2}$; Zaida Cristiane dos Reis ${ }^{3}$ \\ ${ }^{1}$ Universidade de Caxias do Sul - UCS - Caxias do Sul - Brasil \\ gsmilan@ucs.br \\ ${ }^{2}$ Universidade de Caxias do Sul - UCS - Caxias do Sul - Brasil \\ rogernovello@pop.com.br \\ ${ }^{3}$ Universidade de Caxias do Sul - UCS - Caxias do Sul - Brasil \\ zcreis@ucs.br
}

\begin{abstract}
Resumo
$O$ artigo apresenta um estudo sobre a viabilidade financeira e mercadológica do sistema construtivo Light Steel Frame. Devido ao crescimento do setor da construção civil e ao surgimento de novas tecnologias, o estudo busca identificar os aspectos técnicos e mercadológicos deste sistema a fim de compará-lo ao sistema convencional. Assim, são apresentadas informações sobre o sistema além dos atributos de qualidade relevantes identificados junto ao mercado. $O$ estudo conclui ser este um sistema construtivo viável e capaz de gerar um diferencial competitivo, no entanto foi demonstrado que para viabilizar e alcançar tal diferencial, o simples uso do sistema não é suficiente, sendo necessário incorporar métodos de gestão não usuais na indústria da construção civil. Finalmente, são apresentadas diretrizes para viabilização do sistema no mercado, além de considerações para futuros estudos relacionados à evolução do sistema no mercado.
\end{abstract}

Palavras-chave: sistemas construtivos; sistema Light Steel Frame; construção enxuta.

\section{Introdução}

A partir do ano de 2005, o mercado da construção civil vem crescendo no Brasil, cenário que se estende à construção residencial unifamiliar (casas) na região da Serra Gaúcha. Fato este demonstrado pelo número de projetos residenciais aprovados na Prefeitura Municipal de Caxias do Sul - RS, que evoluiu de 406 unidades, em 2004, para 1.546, em 2008 (SINDUSCON/RS, 2009a).

Neste contexto, Santos et al. (1996) afirmam que em contraponto ao aumento de demanda junto ao mercado, há notável crescimento na concorrência entre as empresas construtoras e/ou incorporadoras. Sendo assim, o aumento da competitividade tem exigido das empresas brasileiras um melhor aproveitamento de seus recursos por meio da adoção de novas estratégias empresariais. 
No entanto, a construção de pequeno porte no Brasil ainda é predominantemente artesanal, caracterizada pela baixa produtividade e, principalmente, pelo desperdício. Porém, o mercado tem sinalizado que esta situação deve ser alterada e que o uso de novas tecnologias é a melhor forma de permitir a "industrialização" e a racionalização dos processos (FREITAS; CRASTO, 2006; MCLEOD, 2009). Segundo Freitas e Crasto (2006), o caminho para mudar tal quadro passa necessariamente pela construção industrializada, com mão-de-obra qualificada, otimização dos custos mediante a contenção do desperdício de materiais, padronização, produção seriada e em escala, racionalização dos processos e cronogramas rígidos de planejamento e execução.

Em relação a este cenário de necessidade de processos mais eficazes, buscaram-se sistemas de construção de pequeno porte, projetos ambientalmente sustentáveis (ROAF; FUENTES; THOMAS, 2009), que pudessem suprir tais deficiências, possibilitando a criação de um diferencial competitivo para a constituição de uma nova empresa de construção em Caxias do Sul. Dentre as possibilidades, foi escolhido o sistema conhecido internacionalmente como Light Steel Frame.

De acordo com Freitas e Crasto (2006): "O Light Steel Frame (ou Framing), assim conhecido mundialmente, é um sistema construtivo de concepção racional, que tem como principal característica uma estrutura constituída por perfis conformados a frio de aço galvanizado que são utilizados para a composição de painéis estruturais e não estruturais”.

Logicamente, apesar de se apresentar tecnicamente viável, é necessário um estudo para avaliação mercadológica do sistema como alternativa competitiva e de agregação de valor. Cabe destacar que, para Sales (2001), inovações como, por exemplo, o sistema Light Steel Frame, devem ser economicamente viáveis e compatíveis com os condicionantes nacionais, para que a construção industrializada possa ser uma solução real no panorama brasileiro.

Neste sentido, o estudo precisa identificar o custo de uma construção no sistema Light Steel Frame e os respectivos benefícios aos clientes, para que esta relação possa se transformar, de fato, em uma possível fonte de vantagem competitiva. Por ser um sistema relativamente novo, também é necessário um estudo sobre a aceitação deste sistema construtivo pelo mercado.

\section{Referencial Teórico}

\subsection{Da construção tradicional à construção enxuta}

Segundo Koskela (1992), desde o século XIX, a produção era vista apenas como um processo de conversão de entradas (ou inputs, recursos) e uma saída (ou output, produtos). Como característica deste conceito, o valor de um produto é associado, em essência, ao custo dos seus insumos e do processo de transformação (processo produtivo), resultando em esforços de 
minimização de custos dos processos envolvidos, focados na minimização de cada subprocesso separadamente.

Como conseqüência desta visão "segmentada", o processo produtivo tradicional, no mercado da construção civil, apresenta as seguintes deficiências (FORMOSO et al., 2000): (i) não é dada a devida consideração a atividades que não agregam valor no canteiro de obras, mesmo sendo elas responsáveis por uma parcela considerável dos custos; (ii) o controle de produção (construção) e de melhorias tende a ser focado em cada subprocesso em separado, e não no processo como um todo; e (iii) há pouca consideração a respeito dos requisitos (necessidades, desejos e expectativas) dos clientes, resultando em um processo produtivo, algumas vezes muito eficaz, porém, de produtos inadequados, que não satisfazem os clientes.

Em contraponto a isso, desde a década de 90, a construção civil vem avançando em direção a novos referenciais teóricos e, por decorrência, de novas práticas, a partir das filosofias TQM (Total Quality Management), JIT (Just-in-Time) e, principalmente, do STP (Sistema Toyota de Produção) (SHINGO, 1996). Consoante isso, o trabalho de Kostela (1992) foi o referencial mais proeminente para a fundamentação do modelo denominado de Construção Enxuta (Lean Construction) (GLAUCHE, 2005; LEAN CONSTRUCTION INSTITUTE, 2009).

$\mathrm{Na}$ Construção Enxuta, um processo consiste em um fluxo de materiais, desde a matériaprima até a entrega do produto ao cliente final, sendo o mesmo constituído por atividades de transporte, tempo de espera, processamento (planejamento e execução) e inspeção (qualidade) (FORMOSO, 2002). No processo da Construção Enxuta, assim como em toda a filosofia “Lean”, o ponto central é ter o cliente como o centro das atenções e de referências na busca de geração de valor para todos os públicos envolvidos. Desse modo, o processo produtivo só é capaz de gerar valor quando as atividades de conversão ou processamento transformam as matérias-primas (e/ou materiais, em geral) em produtos que contemplem todos os requisitos e que supram as expectativas dos clientes (BARROS, 2005).

Para tanto, conforme Freitas e Crasto (2006) e Mcleod (2009), o uso de novas tecnologias é a melhor forma de alcançar a racionalização de processos e focar as expectativas dos clientes. Entre tecnologias disponíveis, a escolha do sistema Light Steel Frame foi fundamentada por características, tais como: sistema internacionalmente conhecido, insumos totalmente industrializados (que possibilitam controle de qualidade), facilidade na obtenção dos perfis de aço no mercado nacional e facilidade de montagem (FREITAS; CRASTO, 2006; LEAN CONSTRUCTION INSTITUTE, 2009).

Para facilitar a compreensão do sistema construtivo em estudo, segue uma imagem ilustrativa (Figura 1). 


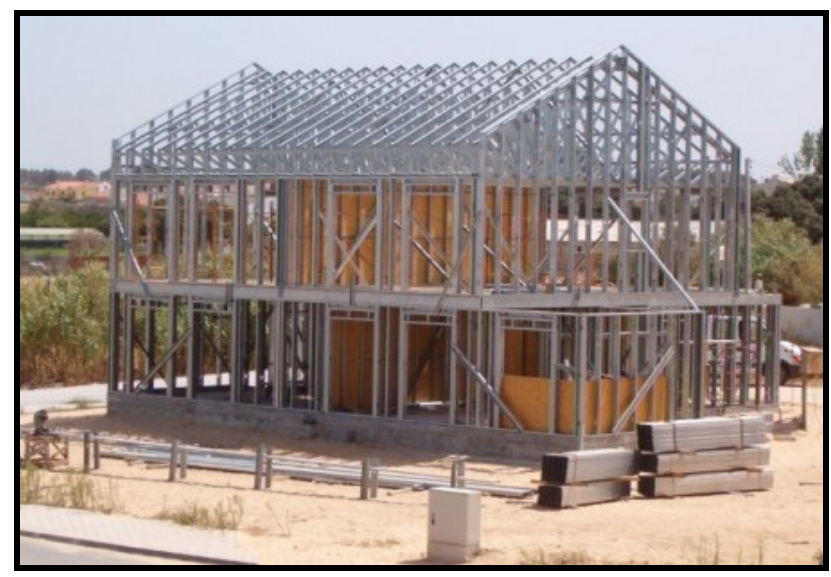

Fonte: Wikipédia (2009).

Conceitualmente, o sistema tem características que facilitam a gestão dos processos dentro dos princípios listados por Kostela (1992) como básicos na Construção Enxuta:

a) Agregação de valor: gerir o projeto focando no aumento de valor para os clientes. Este princípio deve estar incorporado tanto no projeto do produto (imóvel), quanto na gestão da produção (construção);

b) Redução de variabilidade: pelo fato de ser um produto único, a variabilidade na construção traz menor incerteza ao processo. Diminuir esta variabilidade aumenta a confiabilidade do processo e o controle de qualidade do produto;

c) Reduzir atividades que não agregam valor: ao reduzir as atividades que não agregam valor, racionalizam-se os custos;

d) Menor tempo de ciclo (lead time): a diminuição do lead time agiliza a entrega do produto ao cliente, facilita a gestão, aumenta o efeito do aprendizado, torna a produção mais estável e diminui as vulnerabilidades no que tange a mudanças de demanda;

e) Simplificação de processos, partes e componentes: ao diminuir o número de passos (ou etapas) em um processo produtivo (ou de construção), tende a ser menor o número de atividades que não agregam valor;

f) Maior transparência do processo: o aumento da transparência visa tornar os erros do sistema de produção mais fáceis de serem identificados e corrigidos, ao mesmo tempo em que aumenta a disponibilidade de informações, facilitando a gestão do processo como um todo;

g) Foco no controle global: o sistema deve ser controlado sob uma ótica global (sistêmica), tendo em vista toda a cadeia produtiva como geradora de valor; 
h) Introduzir melhorias contínuas: componente fundamental das filosofias TQM e JIT, visa, por meio da gestão participativa dos processos, focar o esforço para a redução de perdas e agregação de valor.

Finalmente, o último aspecto importante na escolha pelo sistema Light Steel Frame está no fato deste ser aceito em financiamentos bancários, ainda mais pelo sistema de financiamento da casa própria no país pela Caixa Econômica Federal (CEF), principal agente financiador do setor.

\subsection{Métodos de custeio e sua aplicação na diminuição de perdas}

Segundo Padoveze (2000), método de custeio é o processo de identificar o custo unitário de um produto a partir dos custos diretos e indiretos. Existem basicamente três métodos de custeio, baseados na classificação e comportamento dos custos:

a) Custeio por absorção: método tradicional onde se consideram os gastos diretos, indiretos, fixos e variáveis. É o método obrigatoriamente utilizado em relatórios contábeis oficiais, como o Balanço Patrimonial e Demonstração do Resultado do Exercício (DRE);

b) Custeio variável ou direto: método de custeio onde são coletados os custos e despesas diretamente relacionadas ao produto (custo de mão-de-obra direta e de matéria-prima). Já os custos indiretos de produção não são alocados aos produtos e são tratados como despesas do período (BARROS, 2005);

c) Método de custeio ABC (Activity Based Costing): método definido por Martins (2003) como sendo uma metodologia de custeio que procura reduzir distorções provocadas pelo rateio arbitrário dos custos indiretos. Este método de custeio inicia pela correta identificação das atividades e seus respectivos direcionadores de custo, ou seja, aquelas atividades que interferem nos custos dos diversos produtos da empresa. Na seqüência, distribuem-se os custos de acordo com esses direcionadores e por último se procede ao rateio final (KAPLAN; NORTON, 1997).

Ressalta-se que, Formoso et al. (2000) apontam que o método de custeio direto é adotado nos orçamento dentro da filosofia tradicional de construção, que são tipicamente segmentados por produtos intermediários (vigas, paredes, etc.). Também é utilizado nos planos de obra nos quais são apresentadas apenas as atividades de conversão.

Barros (2005) comenta que, inicialmente, a contabilidade de custos se preocupou em mensurar monetariamente os estoques e resultados das empresas industriais, ignorando o potencial da contabilidade de custos no campo gerencial. Esta posição foi contundentemente criticada por Johnson e Kaplan (1993), desencadeando um processo de reconhecimento da necessidade de novas práticas de contabilidade gerencial que servissem efetivamente como apoio aos gestores. 
Atualmente, a contabilidade é notada como valioso instrumento gerencial e como ferramenta de avaliação do desempenho de uma organização.

Em acréscimo, Leone (2000) conceitua a contabilidade de custos como um conjunto de procedimentos empregados na determinação do custo de um produto e das várias atividades relacionadas à sua fabricação e venda, auxiliando no planejamento e mensuração de desempenho. Ela tem como finalidade última a prestação de informações de custos para auxiliar os gerentes a administrar as parcelas da atividade empresarial a seu cargo.

Neste sentido, Isatto (2003) destaca que nos últimos anos se tem buscado a incorporação de métodos de custeio inovadores em sistemas gerenciais de custos devido à inadequação dos métodos tradicionais na tarefa de guiar ações de melhoria contínua. Na construção civil esta ação tem destacado o método ABC e seu derivado, o ABM (Activity Based Management) (vide KAPLAN; COOPER, 2000) como forma de custeio mais adequada ao uso gerencial. O mesmo autor ressalta que particularmente no contexto de melhoria de processos produtivos na construção civil, é necessário considerar o sistema $\mathrm{ABC}$ a partir de uma visão mais ampla no que se refere aos princípios e pressupostos envolvidos.

Dentro destes conceitos é importante definir o método de custeio adequado para uma aferição realista de custos que possa ser utilizada como ferramenta gerencial. Mesmo no caso da estratégia de manufatura situar-se, dentro do identificado por Porter (2003), ou como uma estratégia baseada em diferenciação ou em liderança em custo, o custo, que irá balizar os preços de vendas, é um importante critério qualificador que necessita estar dentro dos padrões ou das expectativas aceitas pelo mercado para o sucesso das empresas.

\subsection{A importância de novos produtos como diferencial competitivo}

A gestão de qualidade consiste na possibilidade de criação de uma vantagem competitiva sustentável, por meio do constante aprimoramento do processo de identificação e de atendimento das necessidades, dos desejos e das expectativas dos clientes quanto aos produtos e/ou serviços demandados, e da utilização eficiente de recursos existentes de modo a agregar o máximo de valor possível ao resultado final (BARROS, 2005; MCLEOD, 2009; ROAF; FUENTES; THOMAS, 2009).

Nesta direção, De Toni, Milan e Schuler (2006) afirmam que o desenvolvimento de novos produtos vem sendo considerado como um meio importante para a criação e manutenção de um nível adequado de competitividade das empresas junto ao mercado. A implementação de novos produtos sustenta, segundo Kotler e Keller (2006), a expectativa das empresas em aumentar sua fatia de mercado (market share) e melhorar sua lucratividade e rentabilidade. No entanto, este autor 
salienta, também, que as necessidades e os desejos dos clientes ou consumidores são aspectos fundamentais, o ponto de partida para se procurar novas idéias.

É oportuno comentar que, uma vantagem competitiva emerge pela criação de valor ao cliente. Para Porter (1990), valor é aquilo que os compradores estão dispostos a pagar pelo que a empresa lhes oferece, ou, seja, cada indivíduo estabelece o valor do produto ou serviço adquirido em função do benefício agregado por este produto ou serviço.

$\mathrm{O}$ mesmo autor também afirma que uma das questões centrais relacionadas à estratégia competitiva é a posição da empresa no seu mercado, existindo dois tipos básicos de vantagem competitiva: por custo e por diferenciação, que se desdobram em quatro estratégias genéricas: liderança em custos, diferenciação, enfoque em custo e enfoque em diferenciação.

Dentro das estratégias competitivas genéricas, Slack (1993) conceitua os fatores que direcionam a aquisição do produto e classifica os critérios como:

a) Ganhadores de pedido: principais indicadores utilizados pelos clientes na decisão da compra;

b) Qualificadores: aqueles que precisam estar dentro de certos valores para que os clientes considerem o produto e/ou serviço no momento da escolha. Se o desempenho estiver abaixo do nível qualificador não estará apto a resultar em uma venda. Se estiver muito acima não resultará em aumento significativo de vendas;

c) Menos importantes: critérios que não influem na decisão de compra.

Considerando tal contexto, o trabalho avaliou a segmentação de mercado ideal para o posicionamento competitivo do sistema Light Steel Frame como novo produto capaz de gerar valor aos clientes junto ao mercado em estudo.

\section{Método de pesquisa}

\subsection{Caracterização do ambiente de pesquisa}

A pesquisa foi desenvolvida no mercado de construção civil da cidade de Caxias do Sul, no estado do Rio Grande do Sul (RS). Este mercado apresentou nos anos de 2004 a 2007 um crescimento de 380\% no número de construções residenciais (SINDUSCON/RS, 2009a), fato que demonstra o grande crescimento deste setor no município.

No estado do RS, por sua vez, em todo o setor da construção civil, houve, em 2008, um crescimento de 7,30\% sobre o ano anterior (2007), e apesar da diminuição dos empreendimentos resultantes da crise, o ano de 2009 aponta uma projeção positiva de crescimento, estimada em $3,50 \%$ (SINDUSCON/RS, 2009c). 
Para o ano de 2009, a projeção nacional de crescimento deste setor é de 5\% (FGV, 2009), devido principalmente ao crédito imobiliário, que em 2008 totalizou 35,60 bilhões (ABECIP, 2009). O crescimento do déficit habitacional deve impulsionar ainda mais a liberação de crédito e o crescimento do setor. Estes números se confirmam pelo aumento no nível nacional de emprego do setor, que em agosto de 2009 bateu novo recorde, atingindo 2,26 milhões de trabalhadores, 2,03\% acima do mês de julho (SINDUSCON/SP, 2009).

Apesar do crescimento do setor e da oferta de imóveis, estima-se que devido ao crescimento demográfico, o déficit habitacional em todo o Brasil passe de 7,60 bilhões em 2009 para 22,6 bilhões de residências em 2020 (ABRAMAT, 2009).

\subsection{Objetivos da pesquisa e procedimentos adotados}

O objetivo geral do estudo é a analise da viabilidade financeira e mercadológica do uso do sistema Light Steel Frame na cidade de Caxias do Sul - RS. Em acréscimo, foram definidos os seguintes objetivos específicos:

a) levantar os benefícios e os custos de construção no sistema em estudo;

b) pesquisar critérios ganhadores de pedido para obras residenciais e avaliar a aceitação de sistemas inovadores para clientes residenciais;

c) comparar a relação custo versus benefícios entre o sistema Light Steel Frame e o sistema tradicional;

d) propor diretrizes para a viabilização da construção em Light Steel Frame na cidade de Caxias do Sul - RS.

\subsection{Técnicas e procedimentos de pesquisa adotados}

O método utilizado foi a pesquisa qualitativa, de caráter exploratório. Baseou-se nos preceitos de Cooper e Schindler (2003), que apontam que o caráter exploratório visa prover o pesquisador de maior conhecimento sobre o problema em perspectiva, sendo apropriado para os estágios iniciais quando a compreensão do fenômeno é pequena e o pesquisador não tem conhecimento suficiente para formular hipóteses de pesquisa. $\mathrm{O}$ mesmo autor destaca que a pesquisa de caráter exploratório utiliza métodos bastante amplos e versáteis que compreendem: levantamento de fontes secundárias (dados bibliográficos, documentais, levantamento de estatísticas, levantamento de pesquisas efetuadas e levantamento de experiências) e fontes primárias, opinião compartilhada também por Malhotra (2006).

No sentido de definir a problemática da pesquisa, buscou-se inicialmente conhecer o cenário da construção civil no Brasil por meio do levantamento de dados secundários, principalmente em órgãos públicos e privados ligados a este setor. Este procedimento contempla o proposto por 
Malhotra (2006), de que a definição do problema estabelece o curso de todo o projeto de pesquisa, sendo o aspecto mais importante do processo de pesquisa.

O levantamento de dados através de fontes secundárias aliado a fontes primárias buscou também identificar o sistema construtivo proposto e conhecer suas vantagens e desvantagens em relação a um sistema de construção convencional. Em complemento, a revisão bibliográfica veio embasar os conceitos relativos ao sistema em estudo, com o intuito de dar consistência e aperfeiçoar a definição dos objetivos de pesquisa.

A partir disto, foram aplicadas entrevistas individuais em profundidade com uma abordagem semi-estruturada, empregando um roteiro básico de questões (RIBEIRO; MILAN, 2004). Para as entrevistas, foram selecionados profissionais ligados ao setor da construção civil da cidade de Caxias do Sul - RS, assim como pessoas que já utilizaram o sistema na construção de suas residências atuais e empresas especializadas no sistema Light Steel Frame, que atuam em outras regiões do Brasil.

Para a obtenção dos dados gerais de valor junto aos clientes, a pesquisa também foi aplicada com pessoas em processo de compra de uma residência, ou que passaram recentemente por este processo. Foram pesquisados compradores das classes $\mathrm{A}$ e $\mathrm{B}$, escolhidos devido às características do sistema Light Steel Frame. A partir disto, os dados obtidos nas entrevistas foram analisados, com o intuito de reconhecer em quais segmentos de mercado o sistema Light Steel Frame poderia ser melhor posicionado.

Com a segmentação direcionada e com os demais dados obtidos nas entrevistas, foi traçada uma matriz de valor para relacionar os critérios "ganhadores de pedido" no mercado de construção residencial, com base no modelo proposto por Slack (1993). Finalmente, o resultado desta matriz foi confrontado com os números de mercado do segmento identificado para demonstrar a viabilidade mercadológica do sistema construtivo em estudo.

\section{Desenvolvimento da pesquisa}

\subsection{Custos, benefícios e a relação de valor do sistema Light Steel Frame}

Os custos de construção no sistema Light Steel Frame são similares ao de uma construção convencional, podendo ter custo menor para construções acima de 100,00m² (KISS, 2009). Para construções em padrão médio-alto, a obra pode chegar a um custo entre R $\$ 900,00$ e R \$1.100,00 ao

$\mathrm{m}^{2}$. O mesmo padrão construtivo no sistema convencional tem um custo estimado de $\mathrm{R} \$ 1.215,85$ ao $\mathrm{m}^{2}$ (SINDUSCON/RS, 2009b).

É importante salientar que a definição de custo por $\mathrm{m}^{2}$ de obra é uma maneira genérica e pouco precisa, devido ao fato de cada projeto ter características peculiares, que influem diretamente 
no custo total da obra. Deste modo, para estimar os custos de forma mais precisa, foi desenvolvido um orçamento sobre um projeto de residência de padrão normal R1-N, conforme especificações da NBR 12.721/2006 (ABNT, 2006). A construção, hipoteticamente (vide Figura 2), possui dois pavimentos, com quatro dormitórios, dois banheiros, garagem e área total de $261,00 \mathrm{~m}^{2}$. A escolha deste projeto foi baseada nas características apontadas pelo estudo como ideais para a construção no sistema Light Steel Frame.

Figura 2 - Planta baixa e fachada do projeto utilizado para orçamento

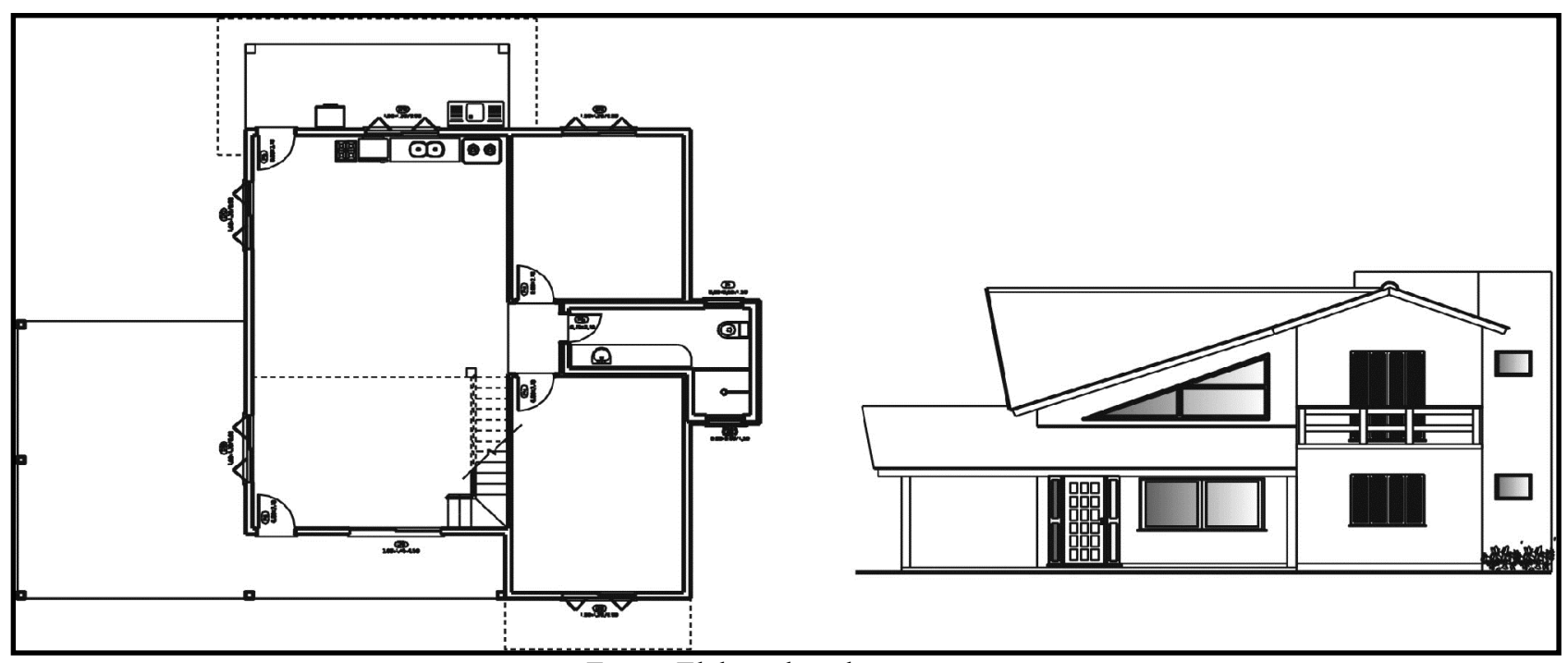

Fonte: Elaborada pelos autores.

Para a comparação destes custos, levou-se em conta o fato do sistema Light Steel Frame possuir maior facilidade de controle devido à menor variabilidade de processos. Também é oportuno salientar que tal sistema apresenta menor consumo de energia resultante da ausência total do uso de água e de movimentação de materiais pesados, características estas que resultam em menores custos indiretos em relação a uma construção com sistema convencional.

O orçamento apontou uma diferença a maior de $2,74 \%$ sobre os custos relativos ao sistema Light Steel Frame e o sistema convencional. Os custos unitários (por $\mathrm{m}^{2}$ ) e totais, de ambos os sistemas, são apresentados na Tabela 1:

Tabela 1 - Custos de construção em cada sistema

\begin{tabular}{l|c|c}
\multicolumn{1}{c}{ Tipos (Sistemas) de Construção } & Custo por $\mathbf{~ m}^{\mathbf{2}}(\mathbf{e m ~ R} \mathbf{S})$ & Custo Total (em R\$) \\
\hline Convencional & 985,80 & $257.293,80$ \\
\hline Light Steel Frame & $1.012,84$ & $264.351,24$ \\
\hline
\end{tabular}

Fonte: Elaborada pelos autores a partir de dados provenientes da pesquisa.

Em relação aos benefícios, o sistema Light Steel Frame possui uma série de vantagens técnicas, que podem ser analisadas em dois grupos: as vantagens relativas à gestão do processo produtivo (construção) e as vantagens agregadoras de valor aos clientes. 
No que diz respeito ao processo produtivo, o sistema possui características que facilitam o gerenciamento da produção e do controle de qualidade em toda a cadeia: insumos industrializados fabricados sob normas de qualidade, padronização/modulação de medidas e utilização de mão-deobra especializada. Tais características facilitam a gestão do processo de construção em consonância aos preceitos da Construção Enxuta. Além disso, segundo o engenheiro Hécio Hernandes, da empresa Steel Frame Engenharia, a diminuição do lead time resultante das características do sistema repercute em custos ainda mais vantajoso quando se trata de tempo de obra, custo financeiro e antecipação de uso e receitas.

Quanto ao cliente final, a pesquisa apontou que as principais vantagens do sistema estão na melhor qualidade dos acabamentos, menor tempo de entrega da obra, maior área útil (paredes de menor espessura) e melhorias no conforto térmico e acústico. Ambientalmente, o sistema também é superior por gerar menor quantidade de resíduos, menor consumo de energia na movimentação de materiais, e menor impacto na implantação da obra. Devido ao maior isolamento térmico, a redução de custos também acontece durante a vida útil da construção pela diminuição do consumo de energia na climatização dos ambientes. Por fim, o estudo demonstrou, ainda, que a possibilidade de reutilização da construção, por meio de ciclos de desmontagem e remontagem pode estar aliada à diminuição dos resíduos na direção de um diferencial como solução ambientalmente correta.

Para avaliação dessas vantagens agregadoras de valor para os clientes, as entrevistas foram elaboradas para reconhecer as dimensões de qualidade percebidas pelos clientes, adaptando os aspectos apontados pelos especialistas entrevistados às oito dimensões de qualidade de Garvin (1992). A inserção destas informações sobre a matriz de valor de Slack (1993) (vide Figura 3), demonstra que o atributo custos, é o único posicionado no limite da zona de ação urgente, devido ao fato de ter grande importância para o cliente e desempenho similar ao sistema de construção convencional. A estética (design) foi apontada como qualificadora, mas devido ao desempenho igual ao sistema convencional, situa-se em zona de melhoramento. A qualidade, mesmo sendo apontada como ganhador de pedido, situa-se em zona apropriada por ser mais elevada no sistema Light Steel Frame.

Cabe salientar que, com base no mercado atual do sistema Light Steel Frame no Brasil, a pesquisa foi direcionada para as classes A e B de compradores, podendo ter classe de importância diferente em outras classes sociais (com perfil de compradores diferentes). 
Figura 3 - Percepção dos compradores aos comparar os dois sistemas construtivos

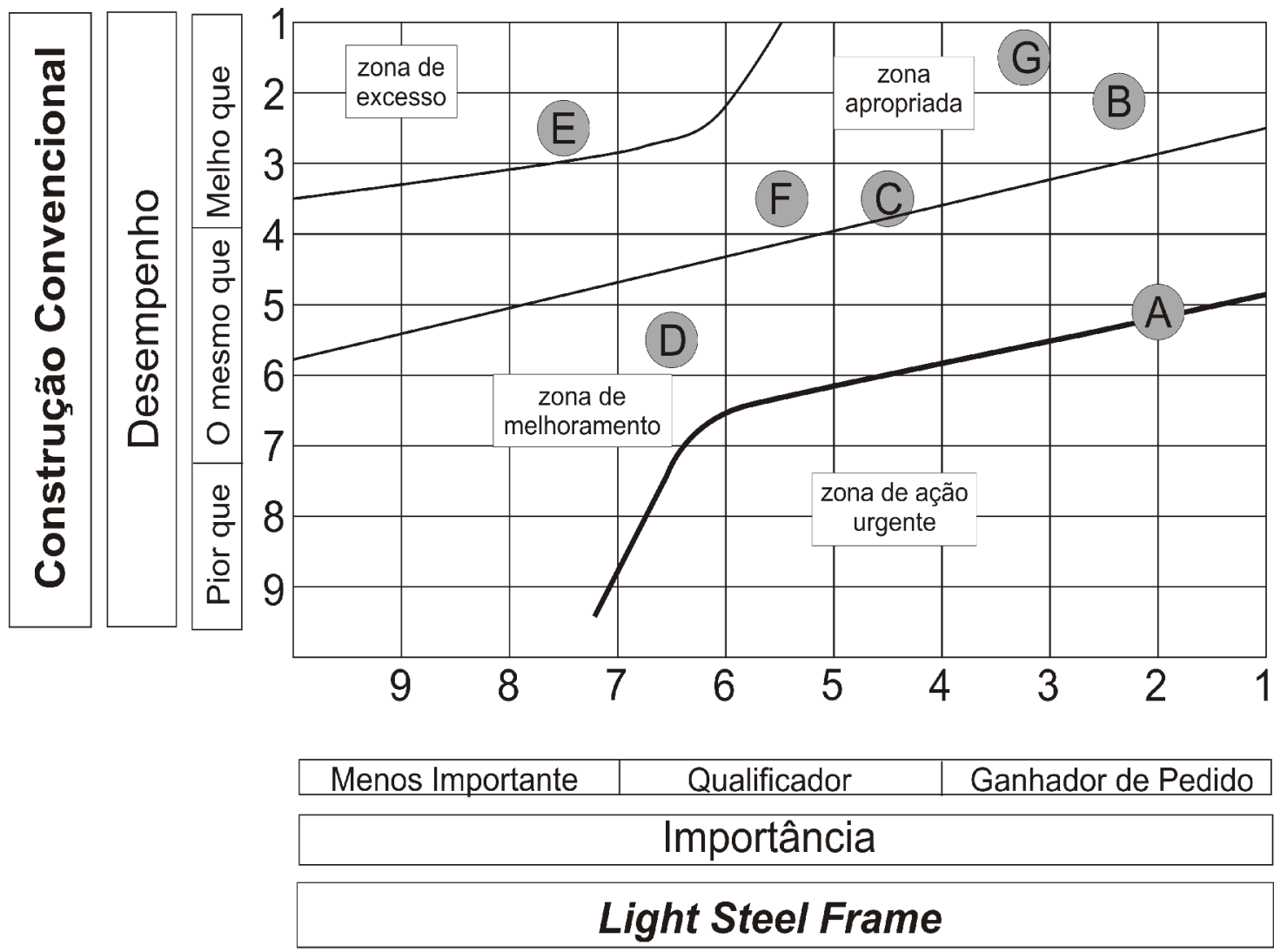

Fonte: Elaborada pelos autores com base nos dados provenientes da pesquisa.

Legenda: A - Preço; B - Qualidade do produto/acabamentos; C - Durabilidade; D - Estética (Design);

E - Velocidade de construção (Prazo de Entrega); F - Confiabilidade de Entrega;

G - Tranqüilidade durante a Construção (menor ocorrência de problemas para o cliente).

\subsection{Viabilidade do sistema em estudo (Light Steel Frame)}

O estudo demonstra a viabilidade tanto técnica quando mercadológica do sistema. Os dados fornecidos pela matriz de Slack (1993), conforme apresentados na Figura 3, apontam que o sistema Light Steel Frame possui dois critérios ganhadores de pedido, em zona apropriada: a qualidade do produto e a tranqüilidade para o cliente. $\mathrm{O}$ mesmo posicionamento ocorre com os qualificadores durabilidade e confiabilidade. O quesito velocidade de construção, embora situado em zona de excesso, não necessita reavaliação, pois é uma característica do sistema e não um trade-off em relação aos custos.

As empresas entrevistadas, que não utilizam o sistema, apontaram em $70 \%$ dos casos o fato do sistema Light Steel Frame ser desconhecido para o grande público, podendo acarretar uma possível barreira devido à insegurança do cliente em relação aos benefícios do sistema. No entanto, especialistas de empresas já atuantes no sistema afirmam haver um aumento gradual na procura pelo Light Steel Frame como alternativa aos problemas usuais da construção convencional. Neste caso, os entrevistados declinaram haver uma predisposição do cliente em buscar informações que lhe tragam segurança para quebrar tal barreira. 
Vale destacar que, todos os entrevistados, em consonância, acreditam que esta barreira é menor entre o público de maior renda e grau de escolaridade, devido ao fato destas pessoas possuírem maior conhecimento do uso destes sistemas em outros países. Os entrevistados também consideram que as camadas de maior renda são as únicas dispostas a pagar um valor maior pelo bem em troca destes diferenciais.

Neste sentido, a análise de valor deixa claro que o posicionamento de mercado deve adotar o enfoque em diferenciação, já que, em relação aos custos, o sistema Light Steel Frame não é capaz, ao menos no estágio atual, de se transformar em um diferencial competitivo para construções isoladas. Desse modo, é indicado o segmento de edificações residenciais acima de $100,00 \mathrm{~m}^{2}$ para a continuidade do estudo.

Na cidade de Caxias do Sul - RS, neste segmento de mercado, foram aprovadas 218 unidades, em 2008, com um total de 38.150,00m² (SINDUSCON/RS, 2009a). Com base na matriz de Slack (1993), é possível avaliar que o Light Steel Frame possui critérios capazes de atuar como ganhadores de pedido, principalmente em relação à qualidade do produto e à tranqüilidade durante o processo de construção. Assim sendo, é possível considerar viável um ganho de ao menos $2 \%$ deste mercado, totalizando $763,00 \mathrm{~m}^{2}$ anuais.

Utilizando o valor de orçamento $\mathrm{R} \$ 1.012,84$ ao $\mathrm{m}^{2}$ (Tabela 1), seria possível atingir, inicialmente, um faturamento total anual de $\mathrm{R} \$ 772.796,92$, o que seria suficiente para viabilizar uma empresa de pequeno porte. Em complemento, as informações provenientes da matriz de valor demonstram haver importantes critérios em zona apropriada e somente um na zona de ação. Isto permite inferir que a adoção de estratégias que aumentem o desempenho dos critérios ganhadores de pedido poderia resultar em maiores ganhos de mercado.

\subsection{Diretrizes estratégicas para viabilização do sistema em Caxias do Sul - RS}

Com base na matriz de Slack (1993), verificou-se que o custo é o critério restritivo ao crescimento do sistema, tornando-se o foco principal da estratégia de manufatura na busca por competitividade. Neste sentido, é de extrema importância o aumento de produtividade para a diminuição de custos através de uma visão mais sistêmica do processo de projeto, planejamento e execução (construção) da obra.

De acordo com Sales (2001) e Freitas e Crasto (2006), grande parte dos problemas e dos custos de construção são devidos a erros de projeto e de planejamento, além da falta de uma concepção sistêmica do processo de produção. Para isto, a racionalização deve ser proporcionada desde a concepção do projeto, pelo uso de coordenação modular, compatibilização entre subsistemas e de projetos de produção. 
Deve ser considerado, ainda, que a construção sobre a qual foi elaborado o orçamento para o estudo é de um projeto arquitetônico não específico para o sistema, sem modulações. O uso de medidas padronizadas no projeto arquitetônico diminui os custos de construção, pois os materiais utilizados, como placas e perfis, possuem medidas padronizadas (SILVA, 2009; LEAN CONSTRUCTION INSTITUTE, 2009).

Outro quesito apontado na zona de melhoramento é a questão estética (design), resultante do fato que os projetos arquitetônicos podem ser executados com o sistema Light Steel Frame com a aparência interna e externa idêntica à de uma construção convencional. Embora este aspecto seja apontado como agente qualificador, pode ser facilmente reposicionado pelo uso de materiais de acabamento típicos do sistema na elaboração de projetos esteticamente diferenciados. Tal estratégia poderia criar uma imagem ou estética de acordo com as expectativas dos compradores sem ser um trade-off com os demais atributos.

Em contraponto, confirmou-se nas entrevistas a necessidade de estratégias voltadas a aumentar a quantidade de informação aos clientes potencias para diminuir as barreiras em relação à aceitação de uma nova tecnologia de construção. Foi identificado que existe uma lacuna importante em relação à imagem da construção em sistema Light Steel Frame e o sistema convencional, e que deve ser trabalhado por meio de um planejamento de marketing capaz de criar uma imagem positiva associada ao produto junto ao seu público-alvo. A inserção de uma marca ou de um novo conceito de produto em uma lacuna de mercado atua como um fator de alavancagem de uma possível vantagem competitiva (GODIN, 2001).

Por serem voltadas a empresas de pequeno porte, tais ações mercadológicas não devem demandar grandes investimentos, trazendo a necessidade de investimentos de marketing não tão elevados, uma vez que as ações devem ser direcionadas e não de massa. Os entrevistados destacaram a importância da propaganda boca a boca como ferramenta de influência para os compradores e de ampliação de mercado das empresas, devido à aceitação e à credibilidade das informações transmitidas aos compradores. Em relação a isso, Godin (2000) afirma que cada vez mais as pesquisas de marketing demonstram que as pessoas tendem a comprar de empresas em que confiam.

Pode-se considerar, então, que a forma tradicional de propaganda não produziria a difusão necessária para criar um número de pedidos capaz de manter e alavancar o crescimento de uma empresa, além de necessitar obviamente de clientes iniciais. Sendo assim, é apropriada a criação de estratégias que concentrem a divulgação em pessoas com influência e interesse suficiente para atuar como disseminadores confiáveis para o público em geral. É claro que, tais formadores de opinião deveriam ser escolhidos pela sua reputação e credibilidade de suas opiniões e pela influência que exercem no público-alvo para o produto. 
Dessa forma, Godin (2000) destaca que o processo de informações cliente-cliente (que inclui a propaganda boca a boca), deve ser amplificado pelo uso correto das tecnologias de informação e da internet. Estas tecnologias proporcionam um canal de comunicação com o cliente de forma contínua e com baixo custo. Tal troca de informações possibilitaria, por sua vez, um maior relacionamento e contato entre a empresa e os clientes, o que poderia estimular a confiança entre as partes também através do boca a boca digital.

Além disso, os especialistas entrevistados apontam como essenciais as garantias pós-vendas e a assistência técnica ampliada, trazendo aos clientes maior segurança e comodidade na aquisição deste tipo de imóvel e na indicação para outros clientes potenciais. Percebe-se, portanto, que cada vez mais os clientes vêm valorizando os serviços agregados aos produtos, principalmente os serviços pós-transacionais ou pós-vendas, aumentando o seu valor percebido e o nível de satisfação dos clientes (MILAN, 2006; MILAN; PAIVA; PRETTO, 2006).

\section{Discussão dos principais resultados}

Este estudo procurou identificar a viabilidade do sistema de construção Light Steel Frame na cidade de Caxias do Sul - RS. Como direcionamento, o estudo guiou-se pelos objetivos específicos como forma de sistematizar a busca pelo seu objetivo geral. Deste modo, o levantamento dos custos, benefícios, critérios ganhadores de pedido e a comparação entre o sistema de construção Light Steel Frame e o sistema convencional foi de vital importância para alcançar as informações desejadas.

Em acréscimo, o entendimento sobre os princípios da construção enxuta e dos métodos de custeio foi essencial para fundamentar o estudo, orientando a análise da viabilidade do sistema analisado. Nesta direção, foi possível identificar as características conceituais do sistema, as quais são de vital relevância para a análise de viabilidade e das diretrizes para a sua viabilização. Tais diretrizes estão inseridas neste contexto, o de incorporar novas teorias e conceitos como forma de aumentar a competitividade através do ganho em eficiência resultante da melhor gestão do processo produtivo. Estes conceitos, embora possam ser utilizados dentro de qualquer método de construção, mostraram-se apropriados para o sistema Light Steel Frame por suas características técnicas.

O estudo aponta que o sistema é uma tecnologia viável para uma empresa de pequeno porte. No entanto, o simples uso desta tecnologia não é suficiente para criar um diferencial competitivo, sendo necessária uma visão sistêmica de todo o processo e um planejamento de estratégias de manufatura e de marketing capazes de difundir as vantagens deste sistema na busca de um diferencial competitivo real.

Para uma melhor amplitude das informações para a tomada de decisões, é pertinente uma análise mais profunda de alguns aspectos abordados. Existem questões importantes que não eram o 
foco ou não puderam ser abordadas neste estudo, mas que influenciam a competitividade do sistema e podem ser objeto de aprofundamento em futuros estudos. Estes aspectos são relativos principalmente aos custos de construção, devido ao fato deste quesito ter sido posicionado em zona de ação urgente na busca por competitividade.

Dentre eles, um estudo da aplicação do método de custeio ABC em uma empresa de pequeno porte, devido ao investimento necessário para o levantamento de custos de cada atividade e o cálculo complexo de custo dentro deste método seria oportuno. Também é relevante um estudo aprofundado sobre a diminuição de custos resultante do uso de modulações e medidas padronizadas. Aliado ao cálculo com maior precisão dos custos indiretos resultantes do método $\mathrm{ABC}$, haveria maior precisão na aferição do custo total, o que poderia possibilitar o reposicionamento do fator custos dentro de zona apropriada, além de sua utilização como critério ganhador de pedido.

Questões tributárias e variações nos preços do aço também podem influenciar diretamente no custo da obra e na competitividade do sistema, uma vez que o aço, conforme orçamento desenvolvido impacta em $24,80 \%$ do custo total da obra. Finalmente, a busca por ganhos de escala deveriam ser considerados no sentido de reduzir os custos de construção. Como o sistema Light Steel Frame utiliza componentes industrializados, a produção em maior escala possibilitaria uma maior produtividade e menores custos de produção.

\section{Considerações Finais}

Além de responder aos objetivos propostos pelo estudo, a pesquisa buscou também trazer referências importantes que possam servir como guia para a pesquisa de viabilidade do sistema Light Steel Frame em outras circunstâncias de mercado. As reflexões desenvolvidas no estudo podem servir como guia para empresas e profissionais ligados à construção civil, direta e indiretamente, que já utilizam ou venham utilizar o sistema Light Steel Frame futuramente, maximizando seus benefícios tanto para as empresas quanto para o cliente final.

Como limitação do estudo, cabe salientar que devido à natureza da pesquisa, foi necessário direcionar a amostra para o principal mercado existente para o sistema no Brasil, construções residenciais para as classes A e B. Este direcionamento, aliado ao tamanho restrito da amostra, não permitiu analisar outras questões, como, por exemplo, a adequação do sistema para outros públicos e outras aplicações construtivas. A ausência de construções em andamento na região, com este sistema, também impossibilitou maiores medições para aferição de custos e a respeito da satisfação de clientes de forma mais precisa.

Neste horizonte, mostra-se pertinente o desenvolvimento de novos estudos para o levantamento dos critérios ganhadores de pedido em construções destinadas a outras atividades, como edificações comerciais ou industriais. Em diferentes situações de mercado, é de se esperar que 
os clientes potenciais tenham diferentes expectativas e/ou percepções, principalmente relativas a certos aspectos, como é o caso do tempo de construção e a confiabilidade de entrega. Por meio de uma nova matriz de valor, resultante de novos estudos, poderia se obter resultados diferentes, ou não, dos apresentados no estudo, podendo abrir-se, assim, uma discussão mais ampla a respeito da viabilidade do sistema.

Um segmento de mercado muito relevante para este tipo de estudo seria o de condomínios de edificações populares. Devido ao programa Minha Casa Minha Vida, com meta de construção de 1 milhão de moradias em todo o Brasil (PROGRAMA MINHA CASA MINHA VIDA, 2009), os ganhos de escala dentro deste padrão construtivo poderia estimular e se configurar em uma oportunidade de mercado. Segundo o CBCA - Centro Brasileiro de Construção em Aço (2009), para que a meta do governo federal seja viabilizada dentro de um prazo razoável, será necessário o uso de sistemas construtivos industrializados. Este segmento de mercado, portanto, é uma outra possibilidade interessante para o estudo dos ganhos de escala como forma de viabilizar o sistema Light Steel Frame inserido em um programa habitacional de amplitude nacional.

\begin{abstract}
The article presents a study on the financial and market viability of the Light Steel Frame constructive system. Due to the growth of the construction industry and the emergence of new technologies, the study aims to identify the technical and market aspects of this system in order to compare it to conventional system. Thus, information is displayed on the system beyond the attributes identified as relevant to the market. The study concludes that this is a constructive system viable and capable of generating a competitive differential, however it was demonstrated that to achieve this differential, the mere use of the system is not sufficient, and it is need to incorporate methods for managing unusual in the construction industry. Finally, it presents guidelines for facilitation of the system on the market, as well as considerations for future studies to the evolution of the system on the market.
\end{abstract}

Key-words: constructive system; Light Steel Frame system; lean construction.

\title{
Referências
}

ABECIP - ASSOCIAÇÃO BRASILEIRA DAS ENTIDADES DE CRÉDITO IMOBILIÁRIO E POUPANÇA. Site institucional. Disponível em: <http://www.sindusconjp.com.br/ informativo/noticia.jsp?idNoticia=339>. Acesso em: 27 ago. 2009.

ABNT - ASSOCIAÇÃO BRASILEIRA DE NORMAS TÉCNICAS. NBR 12.721/2006: avaliação de custos de construção para incorporação imobiliária e outras disposições para condomínios edilícios. Rio de Janeiro: ABNT, 2006.

ABRAMAT - ASSOCIAÇÃO BRASILEIRA DA INDÚSTRIA DE MATERIAIS DE CONSTRUÇÃO. Site institucional. Disponível em: <http://www.sindusconjp.com.br/informativo/noticia.jsp? idNoticia=339>. Acesso em: 27 ago. 2009.

BARROS, E. S. Aplicação da lean construction no setor de edificações: um estudo multicaso. Trabalho de Conclusão de Mestrado. Recife: UFPE, 2005.

CEF - CAIXA ECONÔMICA FEDERAL. Sistemas construtivos utilizando perfis estruturais formados a frio de aços revestido steel framing: requisitos e condições mínimos para financiamento pela Caixa. Disponível em: <http:// www.cbca-ibs.org>. Acesso em: 15 jul. 2009.

CBCA - CENTRO BRASILEIRO DE CONSTRUÇÃO EM AÇO. Site institucional. Disponível em: $<$ http://www.cbca-ibs.org>. Acesso em: 09 jun. 2009. 
COOPER. D. R.; SCHINDLER, P. S. Métodos de pesquisa em administração. 7. ed. Porto Alegre: Bookman, 2003.

DE TONI, D. ; MILAN, G. S.; SCHULER, M. Um estudo exploratório sobre o processo de desenvolvimento de novos produtos. In: MILAN, G. ; PRETTO, M. R. (eds). Gestão estratégica da produção: teoria, cases e pesquisas. Caxias do Sul: EDUCS, 2006. cap. 5, p. 105-121.

FGV - FUNDAÇÃO GETULIO VARGAS. Site institucional. Disponível em: <http://www.sindusconjp.com.br/informativo/noticia.jsp?idNoticia=339>. Acesso em: 27 ago. 2009.

FREITAS, A. M. S.; CRASTO, R. C. M. Steel framing: arquitetura. Rio de Janeiro: IBS/CBCA, 2006.

FORMOSO, C. T. Lean construction: princípios básicos e exemplos. Porto Alegre: NORIE/UFRGS, 2002.

FORMOSO, C. T. et al. Lean construction: diretrizes e ferramentas para o controle de perdas na construção civil. Porto Alegre: NORIE/UFRGS, 2000.

GARVIN, D. A. Gerenciando a qualidade: a visão estratégica e competitiva. Rio de Janeiro: Qualitymark, 1992.

GLAUCHE, R. W. Diretrizes para identificação de gargalos em processos de produção de obras de construção civil residenciais. Trabalho de Conclusão de Mestrado Profissional. Porto Alegre: Escola de Engenharia da UFRGS, 2005 .

GODIN, S. Marketing de permissão: transformando desconhecidos em amigos e amigos em clientes. Rio de Janeiro: Campus, 2000.

GODIN, S. Marketing idéia vírus: como transformar suas idéias em epidemias que irão incendiar o mercado. Rio de Janeiro: Campus, 2001.

ISATTO, E. L. O custeio por atividades na melhoria de processos da construção civil: uma abordagem das suas implicações sob uma perspectiva dinâmica. São Carlos: UFSCar, 2003.

JOHNSON, H. T.; KAPLAN, R. S. Contabilidade gerencial: a restauração da relevância da contabilidade nas empresas. Rio de Janeiro: Campus, 1993.

KAPLAN, R. S.; NORTON, D. P. A estratégia em ação. 15. ed. Rio de Janeiro: Campus, 1997.

KAPLAN, R. S.; COOPER, R. Custo e desempenho: administre seus custos para ser mais competitivo. 2 . ed. São Paulo: Futura, 2000.

KISS, P. Steelcon adapta sistema steel frame ao estilo brasileiro de construir. Disponível em: $<$ http://www.piniweb.com.br/construcao/noticias/steelcon-adapta-sistema-steel-frame-ao-estilo-brasileiro-de-construir78504-1.asp>. Acesso em: 07 set. 2009.

KOSTELA, L. Application of the new production philosophy to construction. Technical Report n. 72 . Stanford: University of Stanford, 1992.

KOTLER, P.; KELlER, K. L. Administração de marketing. 12. ed. São Paulo: Prentice Hall, 2006.

LEAN CONSTRUCTION INSTITUTE. Institutional site. Disponível em: < http://www.leanconstruction.org/>. Acesso em: 20 jul. 2009.

LEONE, G. S. G. Custos: planejamento, implantação e controle. São Paulo: Atlas, 2000.

MALHOTRA, N. K. Pesquisa de marketing: uma orientação aplicada. 4. ed. Porto Alegre: Bookman, 2006.

MARTINS, E. Contabilidade de custos. São Paulo: Atlas, 2003.

MCLEOD, V. Detalhes construtivos da arquitetura residencial contemporânea. Porto Alegre: Bookman, 2009.

MILAN, G. S. Diferenciação por serviços e posicionamento competitivo. In: VIEIRA, G.B.B. (org.). Logística e distribuição física internacional: teoria e pesquisas. São Paulo: Lex Editora (Aduaneiras), 2006. cap. 3, p. 71-95. 
MILAN, G. S.; PAIVA, E. L.; PRETTO, M. R. A relevância do serviço ao cliente como alternativa à diferenciação e ampliação da competitividade das empresas. In: MILAN, G. S.; PRETTO, M. R. (eds.). Gestão estratégica da produção: teoria, cases e pesquisas. Caxias do Sul: EDUCS, 2006. cap. 5, p. 261-282.

PADOVEZE, C. L. Contabilidade gerencial. São Paulo: Atlas, 2000.

PORTER, M. E. Vantagem competitiva: criando e sustentando um desempenho superior. Rio de Janeiro: Campus, 1990 .

. Estratégia competitiva: técnicas para análise de indústrias e da concorrência. 28. ed. Rio de Janeiro: $\overline{\text { Campus, } 2003 .}$

PROGRAMA MINHA CASA MINHA VIDA. Site institucional. Disponível em: $<$ http://www.minhacasaminhavida.gov.br>. Acesso em: 09 out. 2009.

RIBEIRO, J. L. D.; MILAN, G. S. Planejando e conduzindo entrevistas individuais. In: RIBEIRO, J.L.D.; MILAN, G.S. (eds.). Entrevistas individuais: teoria e aplicações. Porto Alegre: FEENG/UFRGS, 2004. cap. 1, p. 9-22.

ROAF, S.; FUENTES, M.; THOMAS, S. Ecohouse: a casa ambientalmente sustentável. 3. ed. Porto Alegre: Bookman, 2009.

SALES, U. C. Mapeamento dos problemas gerados na associação entre sistemas de vedação e estrutura metálica e caracterização acústica e vibratória de painéis de vedação. Trabalho de Conclusão de Mestrado. Ouro Preto: Departamento de Engenharia Civil da UFOP, 2001.

SANTOS, A. et al. Métodos de intervenção para a redução de perdas na construção civil: manual de utilização. Porto Alegre: SEBRAE/RS, 1996.

SHINGO, S. Sistemas de produção com estoque zero: o sistema Shingo para melhorias contínuas. Porto Alegre: Bookman, 1996.

SILVA, V. Steel frame. Revista Arquitetura e Urbanismo. Disponível em: $<$ http://www.revistaau.com.br/arquiteturaurbanismo/185/steel-frame-149630-1.asp>. Acesso em: 07 set. 2009.

SINDUSCON/RS - SINDICATO DA INDÚSTRIA DA CONSTRUÇÃO CIVIL NO ESTADO DO RIO GRANDE DO SUL. Relatório de obras aprovadas na Prefeitura de Caxias do Sul/RS, 2009a.

CUB/RS do mês de agosto de 2009. Disponível em: <www.sindusconrs.com.br/site/imagesdin/226_principaisvariaveis.pdf $>$. Acesso em: 20 set. 2009b.

- Construção gaúcha projeta crescimento para este ano. Disponível em: <http://www.sinduscon-

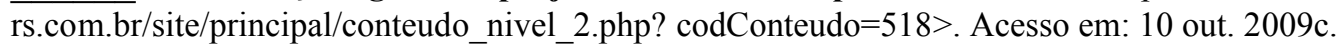

SINDUSCON/SP - SINDICATO DA INDÚSTRIA DA CONSTRUÇÃO CIVIL NO ESTADO DE SÃO PAULO. Site institucional. Disponível em: $<$ http://www.clicrbs.com.br/pioneiro/rs/plantao/10,2668074,Emprego-na-construcaocivil-tem-novo-recorde-em-agosto.html>. Acesso em: 9 out. 2009.

SLACK, N. Vantagem competitiva em manufatura: atingindo competitividade nas operações industriais. São Paulo: Atlas, 1993.

WIKIPÉDIA. Consulta à enciclopédia. Disponível em: <http://www.pt.wikipedia.org/wiki/ Light_Steel_Framing>. Acesso em: 9 jun. 2009.

\section{Nome completo: Gabriel Sperandio Milan}

Filiação institucional: UCS - Universidade de Caxias do Sul

Departamento: Administração

Função ou cargo ocupado: Professor e Pesquisador

Endereço Completo para correspondência (bairro, cidade, estado, país e CEP): Rua: Francisco 
Getúlio Vargas, 1130 - Bloco F - Bairro: Petrópolis - Caxias do Sul - RS - Brasil - CEP: 95070560

Telefones para contato: (54) 3218.21.00

e-mail:gsmilan@ucs.br

Nome Completo: Roger Vagner Novello

Filiação institucional: UCS - Universidade de Caxias do Sul

Função ou cargo ocupado: Arquiteto e Especialista em Gestão Estratégica da Produção

Endereço Completo para correspondência (bairro, cidade, estado, país e CEP): Rua: Francisco Getúlio Vargas, 1130 - Bloco F - Bairro: Petrópolis - Caxias do Sul - RS - Brasil - CEP: 95070560

Telefones para contato: (54) 3213.15.91

e-mail:rogernovello@pop.com.br

Nome Completo: Zaida Cristiane dos Reis

Filiação institucional: UCS - Universidade de Caxias do Sul

Departamento: Administração

Função ou cargo ocupado: Professora e Pesquisadora

Endereço Completo para correspondência (bairro, cidade, estado, país e CEP): Rua: Francisco Getúlio Vargas, 1130 - Bloco F - Bairro: Petrópolis - Caxias do Sul - RS - Brasil - CEP: 95070560

Telefones para contato: (54) 3218.21.00

e-mail:zcreis@ucs.br 